Running Head: TERROR MANAGEMENT AND SELF-AWARENESS

Paul J. Silvia (2001). Nothing or the opposite: Intersecting terror management and objective self-awareness. European Journal of Personality, 15(1), 73-82.

Nothing or the Opposite:

Intersecting Terror Management and Objective Self-Awareness

$$
\text { Paul J. Silvia }
$$

University of Kansas

Made available courtesy of Wiley- Blackwell: http://onlinelibrary.wiley.com/doi/10.1002/per.399/abstract

***Reprinted with permission. No further reproduction is authorized without written permission from Wiley- Blackwell. This version of the document is not the version of record. Figures and/or pictures may be missing from this format of the document. ***

in press, European Journal of Personality

\title{
Paul Silvia
}

University of Hamburg

Psychology Institute II

Von Melle Park 5

D-20146 Hamburg, Germany

email: paulsilvia@ hotmail.com

phone: $01149 \quad 40 \quad 42838 \quad 5408$ 
Abstract

The human capacity for self-awareness allows people to envision their eventual death and thus creates the potential for debilitating anxiety. Terror management research has shown that self-awareness exacerbates the experience of mortality salience. I suggest that self-awareness alone can induce mortality salience through dialectical thinking. If constructs include a concept and its opposite, then focusing on one aspect should also increase awareness of the opposite. Focusing on the existing object self should thus lead to the recognition of the non-existent self that is implied. In Study 1, participants experienced one of two self-awareness manipulations (exposure to a mirror, perceiving the self as distinctive) or no manipulation; mortality salience was measured using a death-relevant word completion task. Both self-awareness conditions reported significantly higher mortality salience than the control condition. In Study 2, participants exposed to their reflection reported increased death-salience and life-salience (as measured by death- and life-relevant word completion tasks) than a control group, which directly suggests that self-awareness leads people to dialectically consider opposing facets of the self. Terror management and objective self-awareness theories might thus be more intimately tied than was previously thought. 
Nothing or the Opposite:

Intersecting Terror Management and Objective Self-Awareness

"Think of nothing or the opposite."

Günter Grass (1977, p. 36)

Terror management theory is concerned with the consequences of considering one's mortality (Greenberg, Solomon, \& Pyszczynski, 1997). Unlike other animals, which have at most rudimentary levels of self-awareness (Hyatt \& Hopkins, 1994; Marten \& Psarakos, 1994), humans can construe a sense of self that can be projected into the future to a time in which the self is inevitably obliterated by death. Such thoughts create the potential for incapacitating anxiety. Much of human behavior and culture presumably operate as buffers against this terror. People can cope with this potential anxiety by participating in ideologies and cultural systems that offer assurances of real or symbolic immortality, which can range from organized religions to idiosyncratic generativity projects (McAdams, 1993).

Self-awareness is thus at the core of terror management. If we don't know that we exist as objects in the world, we can't contrast a self-that-is against a self-that-won't-be. Terror management theory has recognized and highlighted this link. Recent research, for example, shows that mortality salience provokes avoidance of self-awareness (Arndt, Greenberg, Simon, Pyszczynski, \& Solomon, 1998). Persons who experienced heightened mortality salience avoided self-focusing stimuli more than persons who weren't reminded of mortality concerns. As Arndt and his colleagues (1998) suggest:

"Increased self-focus may...augment the individual's concern with controlling the potential for terror because the more aware one is of one's existence, the more salient and inescapable is the problem of possible nonexistence" (p. 1217).

\section{Nothing or the Opposite}

It seems clear that self-awareness enables terror management and exacerbates the press associated with mortality salience. Yet I wish to suggest an even closer relationship between the two theories-self-awareness should itself be capable of inducing an awareness of mortality. This prediction arises from models of dialectical thinking. While people often think in logical propositional sequences based on foundational premises, much of human thought is dialectical —it is reasoning in terms of alternatives, oppositions, associations, and implications (Rychlak, 1968). This is illustrated by the fact that human constructs typically contain embedded and implied opposites (Kelly, 1955), such as common concepts like "tall," "good,” and "difficult.” Utilizing these concepts thus involves employing a dialectic —invoking "tallness" also invokes "shortness" because the concepts reciprocally implicate each other.

Psychologists have recognized for some time that self-knowledge is likewise organized and structured dialectically. The self-concept isn't simply a representation of what the self concretely and momentarily is; it includes representations of what is, isn't, ought, might, could, and hopefully won't be. To consider the self is thus to also consider these alternatives and oppositions. This is most clearly seen when the self is taken as the object of attention (Duval \& Wicklund, 1972). Self-awareness invokes a comparison process that relies on the simultaneous awareness of what is and what could be. The current status of self is viewed against a standard, which represents an alternative that the self “ought” to manifest. Such a comparison couldn’t occur unless the person was holding both the present self and the possible self in mind.

Research on personality judgment further supports a dialectical model of self-evaluation. Lamiell (1987) has argued that people judge the self and others according the target's range of possibilities. When deciding how aggressive someone is, for example, the perceiver compares the target's level of aggression against how aggressive the target could be given the target's other properties, history, and so forth. This dialectical model of judgment is quite different from the non-dialectical model preferred by personality researchers, in which a target's aggressiveness is located within the population distribution of aggressiveness. Research suggests that the dialectical model best describes the judgment process (Lamiell, Foss, Larsen, \& Hempel, 1983).

These ideas quite clearly suggest that self-construal simultaneously involves the present and the possible. How do these notions extend to self-awareness? In Duval and Wicklund's (1972) original 
statement, orienting consciousness toward the self brought about "objective self-awareness." In this state, the person experiences the self as an object in the world, and, consequently, as having properties that are subject to change from outside agents. This state is contrasted with "subjective self-awareness," which results when consciousness is directed away from the self and "the person experiences himself as the source of perception and action" (Duval \& Wicklund, 1972, p. 3). The objectively self-aware person, then, is construing the self as a contemporaneous, bounded, and existing object. The self as an existing object implies a self that does not exist, the self that is versus the self that isn't. ${ }^{1}$ Awareness of the object self thus includes an awareness of the absent, non-existent self. Heightened self-awareness might therefore increase mortality salience, inasmuch as absence and non-being are related to conceptions of death.

If this hypothesis is true, the scope of terror management theory becomes considerably broader. The theory has so far only considered inducers of mortality salience that are directly linked to death, such as introspecting about death (Greenberg, Pyszczynski, Solomon, Simon, \& Breus, 1994). Showing that self-awareness increases mortality salience suggests that terror management concerns are evoked by a wider range of human experiences, even those that might at first seem antithetical to a concern with non-being. More practically, it would lend some weight to past attempts to reinterpret self-awareness theory in terms of terror management (Pyszczynski, Greenberg, Solomon, \& Hamilton, 1990).

\section{Study 1}

The first study sought to demonstrate self-awareness's effects on mortality salience. Participants were exposed to one of several previously-validated self-awareness inductions. One group faced their reflection in a mirror, which is the most widely-used and thoroughly validated manipulation (Carver \& Scheier, 1978). A second group wrote about ways in which they differed from their friends, relatives, and other students. Perceiving the self as novel reliably induces self-awareness because the self becomes figural against the immediate context (Duval, 1976; Mayer, Duval, Holtz, \& Bowman, 1985). This specific manipulation was used and validated in earlier research (Silvia, 2000). A third group encountered no manipulation.

The two different manipulations were used to assess the effect's generality. If only a mirror increases mortality salience, then literally observing oneself as a concrete and corporeal organism is probably needed for self-focus to increase mortality salience. But if construing the self as socially novel also increases mortality salience, then we can be more confident that the relationship stems from general self-awareness processes rather than features of specific manipulations.

\section{Participants and Design}

\section{$\underline{\text { Method }}$}

Thirty undergraduates (12 men, 18 women) who were enrolled in Introductory Psychology participated and received credit toward their research participation option. Participants were randomly assigned to one of two self-awareness conditions (mirror, self-novelty) or a control condition in randomized blocks of six. Separate blocking sets were used for each gender to ensure equal proportions of men and women in each cell.

Procedure

Each person participated individually. The experimenter met the participant and led him or her to a private cubicle. He explained that the study was a simple survey on how personality factors were related to the varieties of college experience. The participant would thus be asked to complete a short questionnaire containing personality scales and questions about different experiences during college. The experimenter left the room to get copies of the questionnaire and returned after three minutes. Participants then completed the questionnaire.

Self-awareness manipulation. In the mirror condition, a large mirror was positioned on the table such that the participant's upper body was reflected. People in this group thus confronted their reflection during the three-minute interval before completing the questionnaire. The mirror was absent in the other two conditions. In the self-novelty condition, the first page of the questionnaire was a self-novelty manipulation developed and validated in earlier research (Silvia, 2000). Participants were asked to list their first name and respond to the following prompts:

1. What is it about you that makes you different from your friends and relatives?

2. What are some ways in which you differ from most other KU students? 
3. Please list 7 traits that you would use to describe yourself.

The first two questions draw attention to novel self-aspects; the third further increases self-reflectiveness (cf. Berkowitz's [1987] self-awareness writing task). In two validation studies (Silvia, 2000), completing this questionnaire led to higher self-focus as measured by a pronoun-selection task (Wegner \& Giuliano, 1983) and the private self-consciousness scale (Fenigstein, Scheier, \& Buss, 1975). The control condition didn't complete this form.

Dependent measures. The questionnaire began with some brief filler scales followed by the measure of mortality salience. The filler scales were intended to further obscure the study's purpose and to distract people from any consciously-experienced mortality concerns (Greenberg et al., 1994). Mortality salience was measured using a word-fragment completion task developed by Greenberg et al. (1994). People are asked to fill in missing letters for word fragments that could be neutral or death-related. COFF__, for example, could be completed as "coffee” or "coffin.” Higher mortality salience is reflected in a greater usage of death-relevant words. Participants completed a set of 15 word fragments, six of which could be completed as death-relevant (coffin, grave, dead, skull, corpse, and stiff) or as neutral (e.g., coffee, grape, deed, skill, course, stint) words.

After completing the questionnaire, participants were probed for suspicion, debriefed, and thanked for their contribution to the research. No one expressed suspicion about the study's true purposes.

\section{Results and Discussion}

A mortality salience index was created by computing the number of words that were completed in their death-relevant form. Initial analyses failed to find main effects or interactions involving gender, all $\underline{F}<<.44$, so it wasn't explored further. As expected, a one-way analysis of variance found significant differences among the three groups, $\underline{F}(2,27)=4.5, \underline{p}<.02$. Focused contrasts using the overall error revealed that both the mirror group, $\underline{\mathrm{t}}(27)=2.9, \mathrm{p}<.01$, and the self-novelty group, $\mathrm{t}(27)=2.0, \mathrm{p}<.05$, each had higher levels of morality salience than the control group. The two self-awareness groups didn’t differ from each other in levels of mortality salience, $\underline{\mathrm{t}}<1$. The means are displayed in Table 1.

Study 1 thus offers initial support for the prediction that "mere self-awareness" can induce mortality salience. An alternative explanation, however, suggests that self-awareness only indirectly influenced mortality salience. High self-awareness is a self-critical state in which the self is compared against standards (Duval \& Wicklund, 1972). Unfavorable comparisons create negative affect, which motivates consistency restoration (Duval \& Lalwani, 1999). If the two inductions made discrepancies salient, the resulting negative affect may have influenced the selection of death-relevant words through affective priming or mood-congruent judgment processes (Gendolla, in press). A second study was thus conducted to test this possibility and to extend the findings of Study 1 .

Study 2

While Study 1 offers suggestive evidence for the role of dialectical thought, the evidence is nonetheless indirect. Study 2 sought to provide direct evidence by measuring both components of the being-nothing dialectic. If objective self-awareness indeed leads people to dialectically consider the self, then both facets of the self should be accessible to the objectively self-aware person. This predicts that both death- and life-relevant thoughts will be simultaneously increased when self-awareness is high. To test this, a "life-relevant" word fragment completion task was developed and included with Study 1's death-relevant word fragments. If the dialectical thinking position is correct, then highly self-aware persons should show an increased tendency to complete the words in their life- and death-relevant forms. An increase in life-salience would also cast doubt on the "negative mood" alternative explanation, inasmuch as the participants' construals of life are positively valenced or at least less negative than death. If self-awareness doesn't increase life salience, then the effect found in Study 1 is probably due to some other process, such as the mood and judgment explanation discussed above.

\section{Participants and Design}

\section{Method}

Forty undergraduates (20 men, 20 women) who were enrolled in Introductory Psychology participated and received credit toward a research option. Participants were randomly assigned to either a high or a low self-awareness condition in randomized blocks of four. Separate blocking sets were used for each gender to ensure equal proportions of men and women in each cell. 


\section{$\underline{\text { Procedure }}$}

The cover story and procedure were essentially similar to Study 1. Participants expected to complete several questionnaires concerning personality and the college experience. Self-awareness was manipulated with a large mirror as described earlier.

Dependent measures. The questionnaire began with some brief filler scales followed by the measures of life salience and mortality salience. The filler scales were intended to further obscure the study's purpose and to distract people from any consciously-experienced mortality concerns (Greenberg et al., 1994). Participants then completed a set of 25 word fragments, including the six death-relevant words (coffin, grave, dead, skull, corpse, and stiff) that were used in Study 1 (Greenberg et al., 1994). Six new word fragments were developed: L_VE, B_, _ IF__, EX__ _ T, A__ _LIVE. These words could be completed as either relevant to living and existing (live, be, life, exist, am, alive) or as irrelevant words (love, by, lift, exalt, at, olive). Thirteen irrelevant word fragments were also included.

Mood measures. Several measures of mood were included to see if negative affect was moderating the effects of self-awareness on mortality salience. The first measure consisted of eight "incentive ratings." Participants were asked to indicate the extent to which they would like to do various fun things (e.g., have coffee with old friends, curl up with a good book). Past research has shown that these incentive ratings are sensitive to changes in positive and negative mood (Clark \& Teasdale, 1985). A second measure of mood asked participants to indicate their current mood on a 21-point bipolar scale ranging from -10 (very negative) to 0 (neutral) to +10 (very positive). Past work (Silvia, 2000; Silvia \& Abele, 2000) has successfully used this measure to discriminate between different mood inductions.

After completing the questionnaire, participants were probed for suspicion, debriefed, and thanked for their contribution to the research. No one expressed suspicion about the study's true purposes.

\section{Results and Discussion}

Mortality salience and life salience indices were created by computing the average number of words completed in their death- and life-relevant forms. The means are displayed in Table 2. As in Study 1, high self-awareness led to higher levels of mortality salience, $\underline{\mathrm{F}}(1,38)=5.25, \mathrm{p}<.028$. The measure of life salience showed a similar pattern; high self-awareness led to a greater proportion of words completed in their life-relevant form, $\underline{\mathrm{F}}(1,38)=5.32, \underline{\mathrm{p}}<.027$. The life and mortality salience scales were significantly correlated, $\underline{\mathrm{r}}=.35, \underline{\mathrm{p}}<.03$. Gender wasn’t involved in any significant main effects or interactions. The heightened levels of both mortality and life salience more directly support the notion that people are dialectically considering the self.

The bipolar mood scale and the incentive ratings were not significantly affected by the self-awareness manipulation, both $\underline{F} s<1$. While they correlated significantly with each other, $\underline{r}=.45$, $\underline{p}<$ .001 , both mood measures failed to correlate with the measures of mortality- and life-salience, all $\underline{\mathrm{r} s}<.14, \underline{\mathrm{p}}<.41$. This pattern of null findings, when taken together with the life-salience effect, suggests that negative mood wasn't responsible for the findings of Study 1.

\section{General Discussion}

The human capacity for self-awareness is by all accounts pan-cultural and innate (Lewis, 1994). Our ability to experience the object self coupled with our ability to represent the inevitable non-existent self creates the potential for death anxiety, which is apparently also pan-cultural (Greenberg et al., 1997). Past research on terror management has considered several intriguing intersections of the two processes, such as the avoidance of self-awareness when one's mortality is salient (Arndt et al., 1998). I have suggested that self-awareness can serve more than an enabling role in terror management processes - it can also be a source of mortality concerns because it leads to a dialectical construal of the self's possibilities. If this is true, then self-awareness is paradoxical: the awareness of eventual non-being is brought about by the awareness of being.

Two experiments demonstrated the effects of self-awareness on mortality concerns. In the first study, persons who encountered their mirror image or perceived themselves as socially distinctive reported higher mortality salience compared to a control group. The consistent effects across two different manipulations suggest that merely examining the body or feeling socially novel are themselves 
insufficient; the effect seems attributable to more general properties of self-awareness. The second study more directly suggests that dialectical reasoning is involved. Persons exposed to their mirror image reported higher mortality salience and life salience. The simultaneous accessibility of cognitions related to life and death is exactly what one would expect if people were reasoning dialectically about the opposing and the possible.

An issue for future research is whether this finding extends to private self-consciousness (Priv SC; Fenigstein et al., 1975). The Priv SC scale typically, though not always, replicates manipulations of self-awareness. This has provided convergent validity for self-awareness studies and assuaged the occasionally disgruntled alliance between social and personality psychology. It is currently unclear what to predict. Recent controversies about what the scale measures suggest that it should be viewed with some skepticism (Creed \& Funder, 1998, 1999; Silvia, 1999). Yet a link between self-focus and mortality salience may be one reason why chronic self-focus is associated with higher depression (Ingram, 1989).

Future work should also examine the cross-cultural generality of the present findings. Implicit self-theories vary idiosyncratically and culturally (White, 1972). When dialectically considering the object self, a person might construe very different implications and oppositions depending upon his or her culturally-inherited theory of self. There are several aspects of an object that can be considered. One opposition of an object is its simple fact of existence. The American sample apparently considered the implied non-existence, which manifested as heightened mortality salience. This isn't surprising, given the tendency of Western cultures to construe persons as autonomous individuals that possess simple dispositions and potentials (Wicklund, 1986). Yet persons from other cultures might dialectically consider another aspect of the object self, such as its boundedness. Such a construal might lead to thoughts of boundlessness, expansiveness, and connection with all things. Another person may consider the self's contemporaneity, which would be opposed by timelessness and the self as infinite and recurring. These theories of self are common in non-Western cultures and religious traditions. Quite different effects would be expected depending upon the specific contents of the dialectical reasoning process. The present findings should not be expected to obtain universally.

\section{Terror Management and Self-Awareness}

Terror management research has shown that mortality salience has broad psychological consequences (Greenberg et al., 1997). The present research suggests that these processes might have an even wider range than was previously thought. Many circumstances that affect self-awareness have no obvious links to traditional mortality salience inducers. Being the only woman in a room of men, feeling a sudden and unexplained bodily change, engaging in absorbing physical activities, and finding oneself immersed and deindividuated in a "baiting crowd" all increase or decrease our awareness of the self as an object existing in the world. Terror management processes might also participate in these situations inasmuch as self-awareness creates mortality salience. This extends the theory's concepts into broader contexts of experience.

Terror management interpretations of self-awareness findings (Pyszczynski et al., 1990) also gain additional teeth from this work. Researchers have suggested that the motive for self-standard consistency derives from the anxiety-buffering functions of an intact cultural worldview. If self-awareness leads to mortality salience, then some phenomena, such as avoidance of self-awareness after failure (Gibbons \& Wicklund, 1976), appear more amenable to the terror management analysis. Yet I doubt that all self-awareness effects result from mortality salience. It seems unlikely, for example, that mortality salience has much to do with the social contagion of self-awareness (Stephenson \& Wicklund, 1984) or enhanced perspective-taking (Stephenson \& Wicklund, 1983). There are also some self-awareness findings that terror management interpretations have yet to address. Recent research, for example, shows that self-aware persons will sometimes change their standards to be congruent with self rather than work toward meeting their standards (Duval \& Lalwani, 1999; Silvia \& Duval, in press). Terror management theory hasn’t yet specified when people will change their cultural worldviews in the service of self-esteem maintenance. Clarifying the overlap between the two intertwined systems is clearly an important task for future inquiry. 


\section{References}

Arndt, J., Greenberg, J., Simon, L., Pyszczynski, T., \& Solomon, S. (1998). Terror management and self-awareness: Evidence that mortality salience provokes avoidance of the self-focused state. Personality and Social Psychology Bulletin, 24, 1216-1227.

Berkowitz, L. (1987). Mood, self-awareness, and willingness to help. Journal of Personality and Social Psychology, 52, 721-729.

Carver, C. S., \& Scheier, M. F. (1978). Self-focusing effects of dispositional self-consciousness, mirror presence, and audience presence. Journal of Personality and Social Psychology, $36,324-332$. Clark, D. M., \& Teasdale, J. D. (1985). Constraints on the effects of mood on memory. Journal of Personality and Social Psychology, 48, 1595-1608.

Creed, A. T., \& Funder, D. C. (1998). The two faces of private self-consciousness: Self report, peer-report, and behavioral correlates. European Journal of Personality, $12,411-431$.

Creed, A. T., \& Funder, D. C. (1999). Shining the light on private self-consciousness: A response to Silvia (1999). European Journal of Personality, $13,539-542$.

Duval, T. S. (1976). Conformity on a visual task as a function of personal novelty on attitudinal dimensions and being reminded of object status of self. Journal of Experimental Social Psychology, 12, 87-98.

Duval, T. S., \& Lalwani, N. (1999). Objective self-awareness and causal attributions for self-standard discrepancies: Changing self or changing standards of correctness. Personality and Social Psychology Bulletin, 25, 1220-1229.

Duval, T. S., \& Wicklund, R. A. (1972). A theory of objective self-awareness. New York: Academic Press.

Fenigstein, A., Scheier, M. F., \& Buss, A. H. (1975). Public and private self-consciousness: Assessment and theory. Journal of Consulting and Clinical Psychology, $43,522-527$.

Gendolla, G. H. E. (in press). On the impact of mood on behavior: An integrative theory and a review. Review of General Psychology.

Gibbons, F. X., \& Wicklund, R. A. (1976). Selective exposure to self. Journal of Research in Personality, 10, 98-106.

Grass, G. (1977). The flounder (R. Manheim, Trans.). New York: Harcourt Brace Jovanovich.

Greenberg, J., Pyszczynski, T., Solomon, S., Simon, L., \& Breus, M. (1994). Role of consciousness and accessibility of death-related thoughts in mortality salience effects. Journal of Personality and Social Psychology, 67, 627-637.

Greenberg, J., Solomon, S., \& Pyszczynski, T. (1997). Terror management theory of self-esteem and cultural worldviews: Empirical assessments and conceptual refinements. Advances in Experimental Social Psychology, 29, 61-139.

Hyatt, C. W., \& Hopkins, W. D. (1994). Self-awareness in bonobos and chimpanzees: A comparative perspective. In S. T. Parker, R. W. Mitchell, \& M. L. Boccia (Eds.), Self-awareness in animals and humans (pp. 248-253). Cambridge, UK: Cambridge University Press.

Ingram, R. E. (1989). Affective confounds in social-cognitive research. Journal of Personality and Social Psychology, 57, 715-722.

Kelly, G. A. (1955). The psychology of personal constructs, Vol. 1: A theory of personality. New York: Norton.

Lamiell, J. T. (1987). The psychology of personality: An epistemological inquiry. New York: Columbia University Press.

Lamiell, J. T., Foss, M. A., Larsen, R. J., \& Hempel, A. (1983). Toward a further understanding of the intuitive personologist: Some preliminary evidence for the dialectical quality of subjective personality impressions. Journal of Personality, 53, 213-235.

Lewis, M. (1994). Myself and me. In S. T. Parker, R. W. Mitchell, \& M. L. Boccia (Eds.), Self-awareness in animals and humans (pp. 20-34). Cambridge, UK: Cambridge University Press.

Marten, K., \& Psarakos, S. (1994). Evidence of self-awareness in the bottlenose dolphin (Tursiops truncatus). In S. T. Parker, R. W. Mitchell, \& M. L. Boccia (Eds.), Self-awareness in animals and humans (pp. 361-379). Cambridge, UK: Cambridge University Press.

Mayer, F. S., Duval, T. S., Holtz. R., \& Bowman, C. (1985). Self-focus, helping request salience, felt responsibility, and helping behavior. Personality and Social Psychology Bulletin, $11,133-144$. 
McAdams, D. P. (1993). The stories we live by: Personal myths and the making of the self. New York: Guilford.

Pyszczynski, T., Greenberg, J., Solomon, S., \& Hamilton, J. (1990). A terror management analysis of self-awareness and anxiety: The hierarchy of terror. Anxiety Research, 2, 177-195.

Rychlak, J. F. (1968). A philosophy of science for personality theory. Boston: Houghton-Mifflin.

Silvia, P. J. (1999). Explaining personality or explaining variance? A comment on Creed and Funder (1998). European Journal of Personality, 13, 533-538.

Silvia, P. J. (2000). Self-awareness and emotional intensity: Testing the salience and dampening hypotheses. Unpublished manuscript, University of Kansas.

Silvia, P. J., \& Abele, A. (2000). Does positive affect induce self-focused attention? Methodological and measurement issues. Manuscript under review.

Silvia, P. J., \& Duval, T. S. (in press). Objective self-awareness theory: Recent progress and enduring problems. Personality and Social Psychology Review.

Stephenson, B., \& Wicklund, R. A. (1983). Self-directed attention and taking the other's perspective. Journal of Experimental Social Psychology, $19,58-77$.

Stephenson, B., \& Wicklund, R. A. (1984). The contagion of self-focus within a dyad. Journal of Personality and Social Psychology, 46, 163-168.

Wegner, D. M., \& Giuliano, T. (1983). On sending artifact in search of artifact: Reply to McDonald, Harris, and Maher. Journal of Personality and Social Psychology, 44, 290-293.

White, R. W. (1972). The enterprise of living: Growth and organization in personality. New York: Holt, Rinehart, \& Winston.

Wicklund, R. A. (1986). Orientation to the environment versus concern with human potential. In R. M. Sorrentino \& E. T. Higgins (Eds.), Handbook of motivation and cognition. New York: Guilford. 
Table 1

Effects of Self-Awareness on Mortality Salience: Experiment 1

\begin{tabular}{|c|c|c|c|}
\hline & \multicolumn{3}{|c|}{ Self-Awareness Induction } \\
\hline & Mirror & Self-Novelty & Control \\
\hline$\underline{\mathrm{M}}$ & 1.8 & 1.5 & 0.8 \\
\hline$\underline{\mathrm{SD}}$ & .79 & .71 & .79 \\
\hline
\end{tabular}

Note. Means represent average number of death-relevant responses; the range is 0 to $6 . \underline{N}=10$ per cell.

Table 2

Effects of Self-Awareness on Life Salience and Mortality Salience: Experiment 2

\begin{tabular}{|c|c|c|}
\hline & \multicolumn{2}{|c|}{ Level of Self-Awareness } \\
\hline & Low & High \\
\hline Life Salience & 1.05 & 1.95 \\
\hline Mortality Salience & .75 & 1.5 \\
\hline
\end{tabular}

Note. Means represent average number of life- and mortality-relevant responses; the range is 0 to $6 . \underline{N}=20$ per cell. 
Author Note

Correspondence should be addressed to Paul Silvia, Department of Psychology,1415 Jayhawk Blvd., University of Kansas, Lawrence, KS, 66045-7556, USA. Electronic mail may be sent to psilvia@ku.edu.

\section{Footnote}

1. This is essentially a manifestation of Hegel's "first triad," the foundational dialectic in which "being” contradicts "nothing” and is resolved by "becoming” (Rychlak, 1968). 